\title{
Range Relationships of Feral Horses with Wild Ungulates and Cattle in Western Alberta
}

\author{
R.E. SALTER AND R.J. HUDSON
}

\section{Abstract}

Spatial and foraging relationships between feral horses and coexisting ungulates were studied in the foothills of western Alberta. Distribution patterns of horses were compared to those of cattle, elk (Cervus elaphus), deer (Odocoileus hemionus and $\boldsymbol{O}$. virginianus), and moose (Alces alces) using indices of spatial and habitat use overlap. Horses were more ubiquitous in their distribution than any other ungulate and utilized sites also used by other species. Lack of behavioural interactions and dietary differences suggested ecological separation of horses from deer and moose. Although horses and elk both used dry grasslands during winter and spring, competition for forage was minimal due to the low number of elk present. During spring horses occupied some areas later preferred by cattle but range use was not excessive prior to the turn-out of cattle. There was little contemporaneous spatial overlap of horses and cattle even though their summer diets showed $66 \%$ overlap. Potential for competition appeared highest between horses and cattle but grazing relationships were complex.

The growing body of knowledge concerning the ecology of feral horses includes several comparative studies on diets of horses, domestic stock and native ungulates (Hubbard and Hansen 1976; Hansen and Clark 1977; Hansen et al. 1977; Olsen and Hansen 1977). A commonly expressed rationale is the need to determine carrying capacities for various combinations of herbivores. However, dietary overlap is important only if accompanied by spatial overlap,

\footnotetext{
Authors are graduate student and associate professor, Dept. of Animal Science, University of Alberta, Edmonton, Alberta, T6G $2 E 3$.

Financial support was through the Forest Development Research Trust Fund, Alberta Forest Service. The authors thank G. Erickson for field assistance during the initial phases of the study.

Manuscript received January 10, 1979.
}

if shared foods are in short supply, or if one herbivore limits access of another to a preferred food source. We report here results of a study to determine the extent of spatial, habitat use and dietary overlap between feral horses and other ungulates in western Alberta, and to determine levels of range utilization.

\section{Study Area}

The study was conducted within $200 \mathrm{~km}^{2}$ of the outer foothills of the Rocky Mountains approximately $30 \mathrm{~km}$ west of Sundre, Alberta. The predominant topographical feature was a series of roughly parallel, forested ridges rising to a maximum altitude of $1,900 \mathrm{~m}$ ASL. Lodgepole pine (Pinus contorta) dominated the forest cover. Meadow and shrub vegetation on a moisture gradient from flooded to dry covered approximately $20 \%$ of the study area, primarily in the valley bottoms and on south-facing slopes. Nine forested habitats, seven meadow/shrub habitats, and one miscellaneous (disturbed) habitat were identified (Salter 1978).

The area supported over 200 resident feral horses during the study. Harvestable populations of white-tailed deer, mule deer, and moose also were present year-round, although no estimates of numbers are available. A primarily cow-calf elk population estimated at approximately 50 animals used the area as winterspring range. Cattle were present between June 15 and October 15 at a permitted stocking rate of 1,500 AUM.

\section{Methods}

\section{Study Design}

We considered late winter to be the critical period for survival of ungulates in this area (Salter and Hudson 1979), and thus focused on this period when determining spatial relationships. 
Supplementary data on year-long distribution patterns of horses and native ungulates were obtained in summer, concurrent with data on cattle distribution. Literature available at the time of the study suggested forage competition would be most likely among the grazing ungulates (horses, cattle and elk) and thus only these species were included in dietary determinations. All quantitative data were obtained within two areas (total $30 \mathrm{~km}^{2}$ ) considered representative of the study area as a whole.

\section{Occupational Patterns}

Occupational patterns were delineated by inspection of 983 temporary macroplots, each $15 \mathrm{~m}$ in diameter and spaced at $100-\mathrm{m}$ intervals along straight line transects. Transects vere located to provide representative coverage of major habitat types. Approximately one half of the plots were examined during January-March 1976, providing information on winter distribution of native ungulates and horses, while the remainder were examined from July-August 1976 for data on distribution of horses and cattle. Habitat type and presence/absence of sign of each species were recorded. Horse pellet groups were aged as spring type (amorphous, bleached and insect-riddled), fresh (moist, green), or unknown during the July-August surveys.

\section{Food Habits}

Diets were determined through analysis of fecal fragments. Fifty horse fecal samples were collected each month during 1976. Seventy-five fresh elk fecal samples were obtained during JanuaryMarch (25 each month). Two hundred samples of cattle feces, representing deposition from mid-June to the date of sampling, were obtained in October. Each sample consisted of approximately $10 \mathrm{~g}$ of material. Composited samples were analyzed by the Composition Analysis Laboratory, Colorado State University.

\section{Range use}

An extensive survey method (Anderson and Currier 1973) was used to examine zones of utilization on all meadows within the areas covered by the macroplot surveys.

During October 1976 each meadow was traversed on foot in a zig-zag fashion, with sufficient coverage to determine the gross pattern of utilization. Use zones representing five classes of herbage utilization were mapped on enlarged aerial photographs and levels of use, stubble heights, and plant community types were recorded for each zone. A 70 ha area that constituted an important winter-spring range for elk and feral horses and a summer range for cattle was re-mapped on June 1, 1977, to establish level of use by feral horses and native ungulates during spring; remaining meadow areas also were re-examined (without mapping) during late May-early June, 1977.

\section{Statistical Analysis}

Distribution of sign on the macroplots was used as a measure of habitat occupancy. All analyses were based on presence/absence of sign (as opposed to absolute abundance) to avoid the assumptions of equal visibility and equal rates of disappearance among habitats and among species. Distribution in relation to habitat availability was examined using chi-square tests. A coincidence index and an association index (Dice 1945), and a coefficient of association $\left(\mathrm{C}_{8}\right.$ : Hurlbert 1969), were used to evaluate the extent of mutual use of plots by horses and each other herbivore. Coincidence indices provide a measure of how much of the combined area used by two species sustained mutual use (i.e., what proportion of sites used by either species $a$ or b were used by both). Association indices indicate the degree of overlap (i.e., what proportion of sites used by a were used by $b$, and vice-versa). C8 values provide a frequency independent measure of association.

Diets of horses were compared to those of cattle and elk using Kulcyznski's similarity index (Oosting 1956), which indicated what percentage of a pair of diets was identical, and Spearman's rank order correlation coefficient (Nie et al. 1975), which indicated to what degree forages were chosen in the same order by a pair of herbivores. One or both of these procedures have been used in previous studies of the interactions of feral horses with other ungulates (Hubbard and Hansen 1976; Hansen and Clark 1977; Hansen et. al. 1977; Olsen and Hansen 1977) and thus provide a standard means of comparison.

\section{Results}

\section{Horse-Deer Relationships}

On a year-long basis horses used $87 \%$ of sites used by deer (primarily mule deer, although some white-tailed deer were present), while deer used $33 \%$ of sites sustaining use by horses (Fig. 1). However, during winter horse sign occurred on only $25 \%$ of sites used by deer. Deer sign occurred on plots in white spruce woods much more frequently than expected, and in dry grasslands and mixed shrub and dwarf birch meadows much less frequently than expected, contrasting with the pattern of winter habitat selection by horses, which avoided white spruce woods and used meadow habitats in proportion to availability (Table 1).

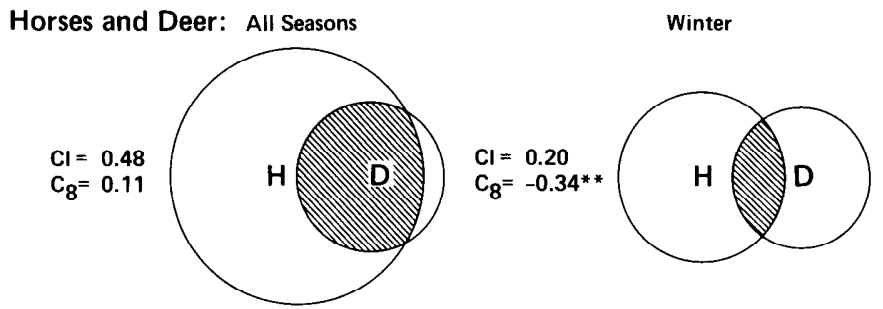

Horses and Moose: All Seasons
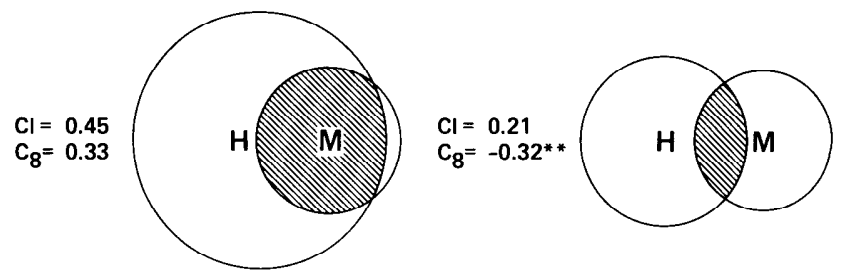

Horses and Elk: All Seasons

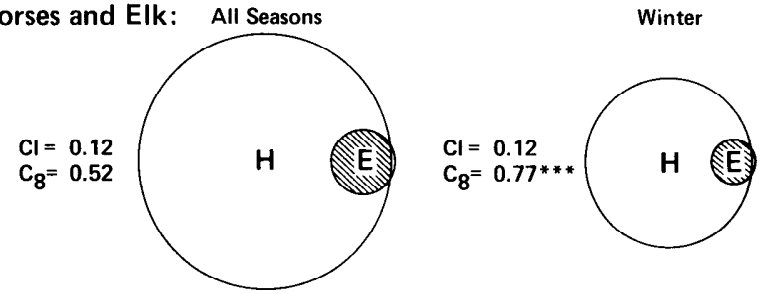

Horses and Cattle: All Seasons (H) - Summer (C)
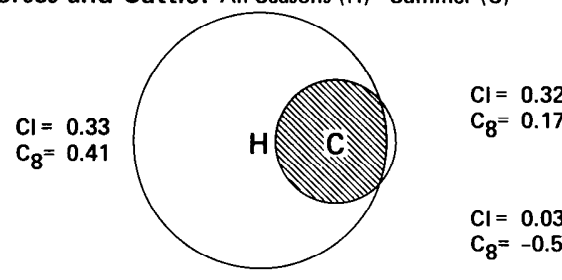

Spring (H) - Summer (C)

$\mathrm{C}_{8}=-0.56$

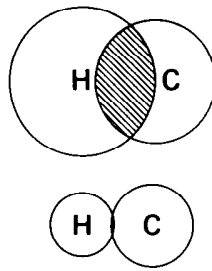

Fresh (H) - Fresh (C)

Fig. 1. Diagramatic representation of spatial overlap of feral horses with native ungulates and cattle. Circles are drawn to scale based on frequency of occurrence of sign in macroplots examined during January-March and July-August, 1976. Proportions of plots receiving mutual use (calculated as association and coincidence (CI) indices) are represented by cross-hatched areas. Each $C_{8}$ value provides a frequency indepdent measure of association that was evaluated hy chi-square probability of obtaining a greater $x^{2}$ value give as: ${ }^{*} 0.05 \geq \mathrm{p}>0.01 ;{ }^{* *} 0.01 \geq \mathrm{p}>0.005$; $\left.{ }^{* * *} \mathrm{p} \leq 0.005\right) . C_{8}$ can vary from -1 to +1 , a zero value indicating that two species are associated as expected by chance. Coincidence and association indices can vary from 0 , representing no association, to +1 , representing complete overlap. 


\begin{tabular}{|c|c|c|c|c|c|}
\hline \multirow[b]{2}{*}{ Habitat type } & \multirow{2}{*}{$\begin{array}{l}\text { Percent of } \\
\text { sampled plots in } \\
\text { habitat type } \\
(n=490)^{2}\end{array}$} & \multicolumn{4}{|c|}{ Percent of plots containing sign in habitat type } \\
\hline & & $\begin{array}{c}\text { Deer } \\
(n=126)\end{array}$ & $\begin{array}{c}\text { Moose } \\
(n=126)\end{array}$ & $\begin{array}{c}\text { Elk } \\
(n=14)\end{array}$ & $\begin{array}{l}\text { Horse } \\
(n=185)\end{array}$ \\
\hline Dwarf birch meadow & 5.3 & $0.0^{-}$ & 7.1 & 14.3 & 6.5 \\
\hline Mixed shrub meadow & 8.5 & $2.4^{-}$ & $18.2^{+}$ & 0.0 & 11.4 \\
\hline Willow thicket & 2.6 & 0.8 & $6.3^{+}$ & 0.0 & 3.8 \\
\hline Dry grassland & 7.5 & $0.8^{-}$ & 5.6 & $50.0^{\prime}$ & 9.7 \\
\hline Dwarf birch thicket & 3.2 & 0.8 & $7.9^{+}$ & 0.0 & 4.3 \\
\hline Mesic pine woods & 1.2 & 2.4 & 0.0 & 0.0 & 0.5 \\
\hline Dry pine woods & 14.4 & 15.1 & 19.0 & 7.1 & $6.0^{1}$ \\
\hline Black spruce woods & 3.0 & 1.6 & 2.4 & 0.0 & $\overline{3.8}-$ \\
\hline White spruce woods & 7.1 & $18.2^{+}$ & 4.0 & 0.0 & $2.2^{-}$ \\
\hline Poplar woods & 4.2 & 3.2 & 0.8 & 14.3 & $7.6^{+}$ \\
\hline Mixed woods & 12.8 & 15.9 & 12.7 & 14.3 & 14.0 \\
\hline Alder thicket & 26.8 & 35.7 & $15.1^{-}$ & 0.0 & 27.0 \\
\hline $\begin{array}{l}\text { Forested watercourse } \\
\text { Total } \chi^{2}\end{array}$ & 1.8 & $\begin{array}{r}1.6 \\
54.6\end{array}$ & $\begin{array}{r}0.0 \\
53.0\end{array}$ & $\begin{array}{r}0.0 \\
44.5\end{array}$ & $\begin{array}{r}2.7 \\
29.0\end{array}$ \\
\hline
\end{tabular}

Thased on presence/absence of tracks or pellet groups in plots examined during January-March 1976. Habitat types contributing 10\% or more to significant total $x^{2}$ values are underlined and marked ${ }^{+}$or ${ }^{-}$to signify preference or avoidance by each species. Value of $\chi^{2}$ at $p=0.05$ is 26.3 .

${ }^{2}$ Other habitats each comprising less than $0.5 \%$ of the total sample were sedge meadow, silver-berry thicket, alpine fir woods and disturbed sites.

Dietary overlap of horses and mule deer was not determined during this study, but reports from other areas indicate that little similarity would be expected. In three studies conducted in Colorado, annual diet similarity ranged from one to $11 \%$ and was usually less than $5 \%$ (Hubbard and Hansen 1976; Hansen and Clark 1977; Hansen et al. 1977).

\section{Horse-Moose Relationships}

On a year-long basis horses used $90 \%$ of sites used by moose, but overlap during late winter decreased to $25 \%$ (Fig. 1).

Although moose preferred mixed shrub meadows, dwarf birch thickets and willow thickets-habitats also frequented by horses (Table 1)-observations suggest separation of the two species on the basis of food selection. Moose were most commonly observed in February, when they browsed during morning in extensive shrubby meadows. Although meadow areas also were utilized for winter feeding by horses, different foods were chosen. The lack of direct evidence of browsing by horses was confirmed by fecal fragments analysis, sedges and grasses proving to be the most important dietary constituents (Table 2). An observation on February 12, 1976, of an adult moose and five horses feeding within $25 \mathrm{~m}$ of each other in a mixed shrub meadow-the moose on shrubs protruding above the snow and the horses pawing for sedges and grasses-suggests ecological separation of these two species during winter even in shared habitats.

Moose rely primarily on browse throughout the year, although grasses occur in the spring and summer diet (Banfield 1974). No comparative studies of horse and moose diets have been reported, but Storrar et al. (1977) found significant ecological separation of the two species in central British Columbia and believed that this was due primarily to differing food habits.

\section{Horse-Elk Relationships}

Horses used $93 \%$ of sites occupied by elk, whereas elk utilized only $6 \%$ of sites used by horses (Fig. 1), reflecting the wider dispersion and greater numbers of the latter within the study area. A similar situation occurred in winter, when there was a highly significant association between the two

Table 2. Percentages of plants in seasonal diets of feral horses, elk, and cattle.

\begin{tabular}{|c|c|c|c|c|}
\hline \multirow[b]{2}{*}{ Forage category } & \multicolumn{2}{|c|}{$\begin{array}{l}\text { Late winter diets } \\
\text { (Jan.-Mar.) }\end{array}$} & \multicolumn{2}{|c|}{$\begin{array}{l}\text { Summer diets } \\
\text { (June-Oct.) }\end{array}$} \\
\hline & norse & Elk & Horse & Cattle \\
\hline Timber oat grass (Danthonia intermedia) & 1 & 1 & 3 & 5 \\
\hline Tufted hair grass (Deschampsia caespitosa) & 1 & - & 2 & 7 \\
\hline Hairy wild rye (Elymus innovatus) & 28 & 19 & 26 & 7 \\
\hline Fescue (Festuca spp.) & 15 & 21 & 23 & 41 \\
\hline Bluegrass (Poa spp.) & 1 & - & 4 & 2 \\
\hline Sedge (Carex spp.) & 35 & 9 & 34 & 27 \\
\hline Wire rush (Juncus balticus) & 4 & - & 2 & $<1$ \\
\hline Cinquefoil-avens (Potentilla-Geum spp.) & $<1$ & 2 & $<1$ & 3 \\
\hline Lodgepole pine (Pinus contorta) & 5 & 22 & 1 & $<1$ \\
\hline Willow (Salix spp.) & $<1$ & 19 & - & $<1$ \\
\hline Horsetail (Equisetum spp.) & 3 & $<1$ & $<1$ & - \\
\hline Moss & 3 & - & $<1$ & 2 \\
\hline
\end{tabular}

Other foods (<3\%) in horse, elk and cattle diets were Koeleria cristata and Schizachne purpurascens; in horse and elk diets Astragalus frigidus, Picea spp., Shepherdia canadensis-Elaeagnus commutata and lichen; and horse and cattle diets Agrostis scabra, Agropyron spp., Bromus spp., Calamagrostis spp., Stipa spp. and Vicia americana. 
Table 3. Percentages similarities and rank correlations of seasonal herbivore diets.

\begin{tabular}{lccc}
\hline \hline Diets & $\begin{array}{c}\text { Percentage } \\
\text { similarity }\end{array}$ & $\begin{array}{c}\text { RHO } \\
\text { values }\end{array}$ & $p$ values' \\
\hline $\begin{array}{c}\text { Horse winter-elk } \\
\text { winter }\end{array}$ & 51 & +0.38 & 0.011 \\
$\begin{array}{c}\text { Horse spring- } \\
\text { cattle summer }\end{array}$ & 67 & +0.57 & 0.001 \\
$\begin{array}{c}\text { Horse summer- } \\
\text { cattle summer }\end{array}$ & 66 & +0.57 & 0.001 \\
\hline
\end{tabular}

'Two-tailed test.

species. During this time elk exhibited a preference for dry grassland habitat, as shown by a higher than expected frequency of sign (Table 1) and by observational data. Nine sightings of elk involving some 84 animals were made during February and March, all but two of these of herds feeding on south-facing grassland slopes. Horses were observed feeding on the same slopes at this time (22 sightings, JanuaryMarch). Evidence of mutual use of winter habitat also was found in two small dwarf birch meadows, where it appeared that elk had followed horses into the area to feed in the same craters. Due to the paucity of elk sign in the study area as a whole, it was not possible to determine the extent of this relationship, or whether it represented commensalism or competition. Winter diets of the two species had some similarity (Tables 2, 3). Hairy wild rye (Elymus innovatus), fescues (Festuca spp.), and sedges (Carex spp.) were important shared constituents. Both coniferous and deciduous browse were important in elk diets but were little used by horses.

The level of dietary overlap between horses and elk was comparable to that occurring in other areas. In Wyoming, horse diets overlapped with those of elk by $52 \%$ in winter, $26 \%$ in spring, $14 \%$ in summer and $70 \%$ in fall (Olsen and Hansen 1977), while in northwestern Colorado dietary overlap of the two species averaged $42 \%$ on an annual basis (Hansen and Clark 1977).

\section{Horse-Cattle Relationships}

Over $90 \%$ of sites utilized by cattle in summer had received prior use by horses (Fig. 1). About $40 \%$ of these sites were used by horses in spring; the remaining $50 \%$ were used in winter or during an undetermined season. However, there was little overlap during the time when cattle were actually present, the coincidence and association indices being low and the $\mathrm{C}_{8}$ value negative (although not statistically significant) when only fresh feces were considered.

Cattle utilized the dwarf birch thicket, willow thicket and dry grassland habitat types more frequently than expected, and the alder thicket types less frequently than expected from their availability within the study area (Table 4). All habitats except dwarf birch meadow were used to some extent. The general pattern of avoidance of the wettest habitats and concentration on dry, open sites, including roadsides, was confirmed by direct observation of cattle.

Horse and cattle diets during the period of cattle occupancy overlapped by nearly $70 \%$ (Table 3 ). Fescues and sedges together constituted over $50 \%$ of the horse diet and nearly $70 \%$ of the cattle diet during this time; the two diets differed chiefly in that horses ate more hairy wild rye (Table 3 ), indicating a greater use of forested habitats. However, open habitats-chiefly mixed shrub meadows-appeared to supply most of the forage utilized by horses throughout the summer.

In order to determine whether horses ate preferred cattle foods in spring, prior to arrival of cattle on the study area, comparisons were made between the April-May diet of horses (Salter and Hudson 1979) and the late June-early October diet of cattle. This pair of diets was $67 \%$ identical, although the order of the two most important forages was reversed-sedges heing most important in the horse diet and fescues being most heavily utilized by cattle.

The high levels of similarity between the diets of horses and cattle agree with results of other studies of these two species (Hubbard and Hansen 1976; Hansen and Clark 1977; Hansen et al. 1977; Olsen and Hansen 1977).

\section{Effects of Combined Range Use}

By late summer $75 \%$ of nonforested habitat was used at a safe or lower level, most of the remaining $25 \%$ receiving heavy utilization (Table 5). This pattern varied according to habitat type. Dry grassland clearly received the heaviest use

Table 4. Distribution of feral horse and cattle pellet groups by habitat type.'

\begin{tabular}{|c|c|c|c|}
\hline \multirow[b]{2}{*}{ Habitat type } & \multirow{2}{*}{$\begin{array}{l}\text { Percent of sampled plots } \\
\text { in habitat type } \\
(n=493)\end{array}$} & \multicolumn{2}{|c|}{$\begin{array}{l}\text { Percent of plots containing all age pellet } \\
\text { groups in habitat type }\end{array}$} \\
\hline & & $\begin{array}{l}\text { Cattle } \\
(n=92)\end{array}$ & $\begin{array}{c}\text { Horse } \\
(n=417)\end{array}$ \\
\hline Dwarf birch meadow & 2.4 & 0.0 & 2.4 \\
\hline Mixed shrub meadow & 6.3 & 9.8 & 7.0 \\
\hline Willow thicket & 1.6 & $8.7^{+}$ & 1.0 \\
\hline Dry grassland & 4.1 & $15.2^{+}$ & 4.8 \\
\hline Dwarf birch thicket & 2.2 & $12.0^{+}$ & 2.6 \\
\hline Dry pine woods & 20.4 & 15.2 & 19.2 \\
\hline Black spruce woods & 2.4 & 2.2 & 2.9 \\
\hline White spruce woods & 4.3 & 3.3 & 3.8 \\
\hline Poplar woods & 3.9 & 6.5 & 4.3 \\
\hline Mixed woods & 16.9 & 16.3 & 18.4 \\
\hline Alder thicket & 32.9 & $5.4^{-}$ & 31.4 \\
\hline Disturbed sites & 1.0 & 4.4 & 0.7 \\
\hline Forested watercourse & 1.4 & 1.1 & 1.4 \\
\hline Total $\chi^{2}$ & & 150.5 & 5.0 \\
\hline
\end{tabular}

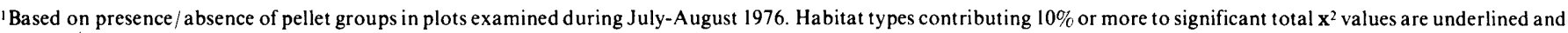
marked ${ }^{+}$or $^{-}$to signify preference or avoidance by each species. Value of $\mathrm{x}^{2}$ at $p=0.05$ is 21.0 . 


\begin{tabular}{|c|c|c|c|c|c|c|c|}
\hline \multirow[b]{2}{*}{ Habitat type } & \multicolumn{5}{|c|}{ Percent of habitat in use class 1} & \multirow[b]{2}{*}{$\begin{array}{r}\text { Habitat area } \\
\text { (ha) }\end{array}$} & \multirow[b]{2}{*}{$\begin{array}{r}\text { Percent } 0 \\
\text { tota }\end{array}$} \\
\hline & $\begin{array}{r}\text { None-very } \\
\text { light }\end{array}$ & Light & Safe & Heavy & Severe & & \\
\hline Dwarf birch meadow & 73.3 & 20.8 & 3.9 & 2.0 & 0 & 68.9 & 17.5 \\
\hline Sedge meadow & 34.7 & 38.8 & 22.4 & 4.1 & 0 & 4.9 & 1.2 \\
\hline Mixed shrub meadow & 8.2 & 55.7 & 19.1 & 11.6 & 5.4 & 115.1 & 29.2 \\
\hline Willow thicket & 0 & 0 & 100.0 & 0 & 0 & 20.8 & 5.3 \\
\hline Dry grassland & 3.1 & 3.9 & 44.9 & 47.2 & 0.8 & 122.9 & 31.2 \\
\hline Dwarf birch thicket & 9.9 & 39.9 & 25.4 & 24.9 & 0 & 60.7 & 15.4 \\
\hline Miscellaneous & 0 & 0 & 0 & 83.3 & 16.7 & 0.6 & 0.2 \\
\hline Total area (ha) & 71.4 & 109.3 & 117.2 & 88.7 & 7.3 & 393.9 & 100.0 \\
\hline Percent of total & 18.1 & 27.7 & 29.8 & 22.5 & 1.8 & 99.9 & \\
\hline
\end{tabular}

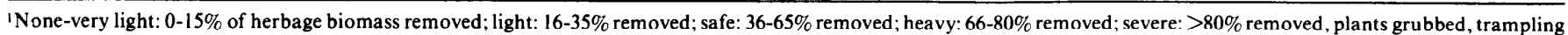
damage evident.

and dwarf birch meadows the lightest, although grazing occurred in all habitats. Combined grazing by horses and cattle caused localized damage along stream courses and around both natural and artificial salt licks (category Miscellaneous, Table 5).

With the exception of some stream courses, wet and mesic habitats generally received limited utilization in summer, in direct contrast to the situation for dry grasslands, dwarf birch thickets and willow thickets-all preferred cattle habitats-which together received the heaviest grazing use. At the end of the summer grazing season, nearly half of the dry grasslands were heavily grazed and nearly all had received some degree of use. Although residual biomass was not measured, stubble heights (usually less than $5 \mathrm{~cm}$ ) indicated that forage available on these areas over winter had been severely reduced. This also was true to a lesser extent for the closely associated dwarf birch thicket type.

In contrast, intensive examination of an important winter-spring range (and cattle summer range) showed that utilization of new growth was none to very light over $95 \%$ of the 70 ha area just prior to the cattle turn-out date. Concentration of foraging activity in other areas resulted in localized grazing and trampling damage (primarily in wet habitats) during spring, but evidence of spring grazing was found on less than $5 \%$ of total meadow habitat.

\section{Discussion}

A primarily descriptive approach was adopted in this study toward determination of spatial, habitat use and dietary relationships of feral horses with coexisting herbivores. It is recognized that when viewed superficially indications of spatial and food habits overlap may be taken as evidence either for or against competition (Sale 1974; Hudson et al. 1976). Overlap may be functionally synergistic, at least in some grazing systems (Bell 1971). Although measures of resource use overlap can only indicate the degree of similarity between species, and do not measure competition directly, the degree of competition and the amount of overlap are directly related when food is in short supply (Sale 1974). Thus, the extent of actual or potential competition can only be inferred when the use of food and space, the level of range utilization and the behaviour and physical condition of the animals are considered together rather than in isolation (e.g., Wilkinson et al. 1976). In the present study, evidence of competition was sought from the condition of the range and from behavioural interactions, interpreted in light of knowledge of spatial and dietary relationships.
Association and coincidence indices revealed the basic spatial relationships between feral horses and other ungulates. Perhaps the most interesting finding was the high frequency of occurrence of multi-season horse pellet groups as compared to those of other species. This may indicate a broad niche and non-specialist strategy of habitat occupation by horses, although their seasonal distribution was decidedly non-random. Diagrammatic representation of spatial relations showed that, on a year-long basis, horses overlapped extensively onto the areas used by all other species. However, consideration of seasonal distribution indicated that much of this overlap was noncontemporaneous.

Strongly expressed competitive interference (i.e., one species blocking another's access to a limited resource) or exploitation (depletion of the food resource by one species) would influence the interpretation of spatial relationships. Behavioural observations provided little evidence for competition through interference in this grazing system (cattle, mule deer, elk and moose all were observed feeding in proximity to feral horses without interaction), but dietary similarities and spatial overlap indicated the potential for exploitation of elk and cattle foods by horses. In contrast, feral horses would be not expected to exploit the food resource of browsing herbivores (moose, mule deer and white-tailed deer), which utilize herbage primarily during early growth stages in spring and summer (Banfield 1974).

The ability of elk to subsist on browse (Kufeld 1973) makes the importance of forage competition between elk and horses difficult to evaluate. Some shared winter foods (hairy wild rye, sedges) were abundant within extensive habitats (Salter 1978). Horses and elk both also used fescues during winter, but although these grasses were in short supply due to previous heavy grazing the extent of competition for them was minimized by the low numbers of elk present. Elk and horses (and to a lesser extent mule deer, white-tailed deer, and moose) utilized succulent green herbage during April-May, but the low incidence of grazing in nonforested habitats indicated that food was being produced more rapidly than it was consumed; in this situation no competition for food occurs (Sale 1974).

Similarly, spring grazing by horses did not deplete ranges preferred later in the season by cattle, but certain common use areas (primarily dry grasslands and dwarf birch thickets) were overgrazed by autumn. Heavy use of these habitats indicated that competition for some forages may have occurred late in the cattle grazing season.

Fescues were likely the key species in competitive 
relationships; of the major shared forages they were the only ones confined largely to the heavily used dry grassland and $\mathrm{d}$ warf birch thicket habitats. Their depletion also may have affected subsequent (winter) distribution and food selection by both horses and elk, but whether there was any effect on population productivity could not be determined. All other shared forage species were widespread and were not overutilized during any season of the year.

While these conclusions are valid for the patterns of resource use documented during the study, the complex and labile nature of range relationships needs tn be emphasized. For example, the use of previously grazed areas by several species in spring illustrated a feedback effect of previous grazing resulting in increased availability of succulent forage early in the next growing season. Conversely, large areas of meadow habitat of apparently similar species composition were ungrazed throughout the year. The stability of this grazing pattern (i.e., the period over which certain areas are heavily grazed, while others remain ungrazed) could not be determined from the information available. This would be influenced by extrinsic factors such as location of artificial salt licks, alterations in cattle distribution through increased management, and control of feral horse numbers.

\section{Literature Cited}

Anderson, E.W., and W.F. Currier. 1973. Evaluating zones of utilization. J. Range Manage. 26: 87-91.

Banfield, A.W.F 1974. The Mammals of Canada. University of Toronto Press, Toronto. 438 p.

Bell, R.H.V. 1971. A grazing ecosystem in the Serengeti. Sci. Amer. 225: 8693..
Dice, L.R. 1945. Measures of the amount of ecologic association between species. Ecology 26: 297-302.

Hansen, R.M., and R.C. Clark. 1977. Foods of elk and other ungulates at low elevations in northwestern Colorado. J. Wildl. Manage. 41: 76-80.

Hansen, R.M., R.C. Clark, and W. Lawhorn. 1977. Foods of wild horses, deer, and cattle in the Douglas Mountain area, Colorado. J. Range Manage. 30: 116-118.

Hubbard, R.E., and R.M. Hansen. 1976. Diets of wild horses, cattle and mule deer in the Piceance Basin, Colorado. J. Range Manage. 29: 389392.

Hudson, R.J., D.M. Hebert, and V.C. Brink. 1976. Occupational patterns of wildlife on a major East Kootenay winter-spring range. J. Range Manage. 29: 38-43.

Hurlbert, S.H. 1969. A coefficient of interspecific association. Ecology. 50: 1-9.

Kufeld, R.C. 1973. Foods eaten by the Rocky Mountain elk. J. Range Manage. 26: 106-113.

Nie, N.H., C.H. Hull, J.G. Jenkins, K. Steinbrenner, and D.H. Bent. 1975. SPSS: Statistical Package for the Social Sciences. McGraw-Hill, New York. $675 \mathrm{p}$.

Olsen, F.W., and R.M. Hansen. 1977. Food relations of wild free-roaming horses to livestock and big game, Red Desert, Wyoming. J. Range Manage. 30: 17-20.

Oosting, H.J. 1956. The Study of Plant Communities. W.H. Freeman and Co., San Francisco. 440 p.

Sale, P.F. 1974. Overlap in resource use and interspecific competition. Oecologia 17: 245-256.

Salter, R.E. 1978. Ecology of feral horses in western Alberta. M.Sc. Thesis, Univ. of Alberta. $239 \mathrm{p}$.

Salter, R.E., and R.J. Hudson. 1979. Feeding ecology of feral horses in western Alberta. J. Range Manage. 32: 221-225.

Storrar, J.A., R.J. Hudson, and R.E. Salter. 1977. Habitat use behaviour of feral horses and spatial relationships with moose in central British Columbia. Syesis 10: 39-44.

Wilkinson, P.F., C.C. Shank, and D.F. Penner. 1976. Muskox-caribou summer range relations on Banks Island, N.W.T. J. Wildl. Manage. 40: 151-162.

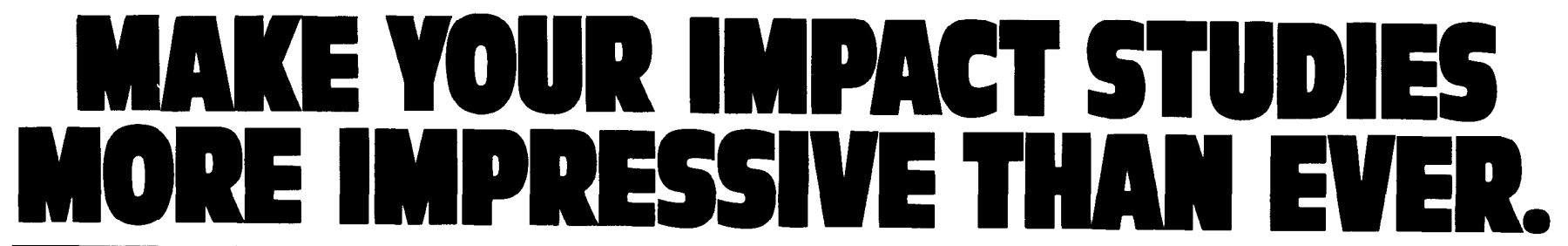

With aerial photographs and a Bausch \& Lomb ZOOM TRANSFER SCOPETM instrument, you can map and plan land use studies quickly, economically, simply.

The Z.T.S. ${ }^{\circledR}$ instrument optically mixes aerial photographs and data base without projection, without expensive darkroom equipment.

It compensates for distortion.

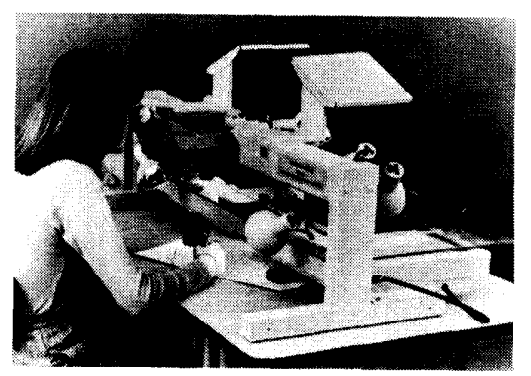

It is compact, lightweight, simple to operate. And much more.

We'll be happy to recommend the instrument that's best for your needs. Call us at (716) 338-6000. Or send coupon for illustrated brochure.

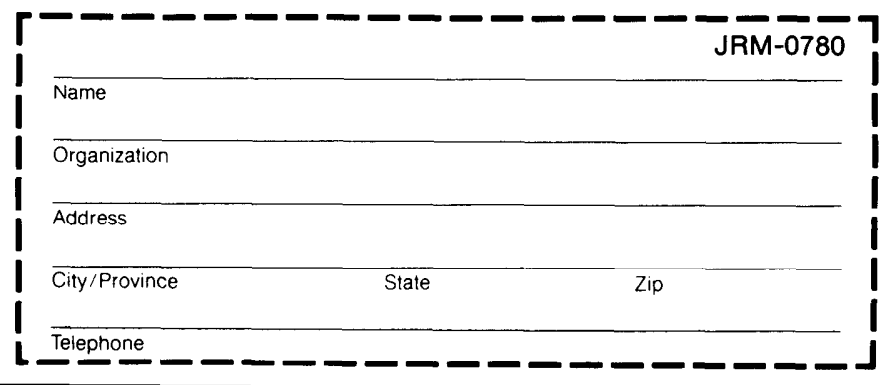

